\title{
Erratum to: Hyperinsulinemia in rats causes impairment of spatial memory and learning with defects in hippocampal synaptic plasticity by involvement of postsynaptic mechanisms
}

\author{
Amer Kamal • Geert M. J. Ramakers • \\ Willem Hendrik Gispen · Geert Jan Biessels
}

Published online: 12 May 2013

(C) Springer-Verlag Berlin Heidelberg 2013

Erratum to: Exp Brain Res (2013) 226:45-51

DOI 10.1007/s00221-013-3409-4

The lead author was inadvertently listed twice in the author group of the original publication. The correct author line should read as:

Amer Kamal, Geert M. J. Ramakers, Willem Hendrik Gispen and Geert Jan Biessels

The online version of the original article can be found under doi:10.1007/s00221-013-3409-4.

\footnotetext{
A. Kamal · G. M. J. Ramakers · W. H. Gispen · G. J. Biessels Department of Neuroscience and Pharmacology, Rudolf Magnus Institute of Neurosciences, University Medical Center Utrecht, Utrecht, The Netherlands

A. Kamal $(\bowtie)$

Department of Physiology, College of Medicine and Medical

Sciences, Arabian Gulf University, P.O. Box 26671,

Manama, Bahrain

e-mail: ameralansari@gmail.com; amerha@agu.edu.bh
} 